\title{
Pemeriksaan Tekanan Darah Dan Konseling Tentang Hipertensi Dan Komplikasinya Pada Lansia Di Desa Kromasan Kabupaten Tulungagung
}

\author{
Siti Suciati, Ernik Rustiana \\ Universitas Tulungagung \\ sitisuciati@unita.ac.id ernikrustiana@unita.ac.id ${ }^{2}$
}

\begin{abstract}
The main problem in various countries related to health is heart disease and blood vessels. Hypnosis is one of the first triggers in the world annually. The number of people with hypertension continues to increase every year. It is estimated that in 2025 there will be 1.5 billion people who suffer from hypertension, and it is predicted that 10.44 million people die annually due to hypertension and its complications. Management of hypertension can be done from the knowledge of the elderly about hypertension and hypertension diet regulation. Activities that have been carried out include providing health education related to hypertension, blood pressure checks, being taught progressive muscle relaxation techniques, and being given an understanding of making cucumber juice and starfruit to control hypertension. The purpose of this activity is expected to be an increase in awareness, knowledge, and behavior of the elderly in a healthy life regarding hypertension so that the elderly realizes the importance of maintaining blood pressure experienced at this time. Community service activities in Kromasan Village, NgunutTulungagungSubdistrict were carried out in September 2019. Of the 110 elderly people present, 41 elderly people were found with blood pressure above normal $(140-90 \mathrm{mmHg})$. It can be said that the prevalence of hypertension is only $37.3 \%$, because other elderly people have been controlled by using anti-hypertensive drugs given from the Ngunut Health Center.
\end{abstract}

Keywords: Hypertension; Elderly; Community Service

\section{Abstrak}

Masalah utama di berbagai negara yang berkaitan dengan kesehatan adalah penyakit jantung dan pembuluh darah. Hipetensi merupakan salah satu pemicu pertama di dunia per tahunya. Angka penderita hipertensi terus mengalami peningkatan setiap tahunya. Diperkirakan pada tahun 2025 akan ada 1,5 Miliar orang yang menderita hipertensi, dan diprediksi per tahunnya 10,44 juta orang meninggal yang disebabkan karena hipertensi dan komplikasinya. Manajemen hipertensi dapat dilakukan dari pengetahuan lansia mengenai hipertensi serta pengaturan diet hipertensi. Kegiatan yang telah dilakukan yaitu memberikan pendidikan kesehatan terkait penyakit hipertensi, pemeriksaan tekanan darah, tehnik relaksasi otot progresif, dan diberi pemahaman tentang pembuatan jus timun dan belimbing untuk mengontrol hipertensi. Tujuan dari kegiatan ini diharapakan ada peningkatan kesadaran, pengetahuan, maupun perilaku lansia sehingga menyadari pentingnya menjaga tekanan darah yang dialami saat ini. Kegiatan dilaksanakan pada bulan September 2019. Dari110 lansia yang hadir, ditemukan 41 orang lansia dengan tekanan darah diatas normal $(14090 \mathrm{mmHg})$. Hal ini dapat dikatakan prevalensi yang memiliki hipertensi hanya 37,3\%, dikarenakan lansia lainnya telah terkontrol dengan menggunakan obat anti hipertensi yang diberikan dari Puskesmas Ngunut.

Kata Kunci: Hipertensi; Lansia; Pengabmas 


\section{A. PENDAHULUAN}

Lansia ialah orang yang mempunyai umur diatas 60 tahun. Diperkirakan populasi lansia yang di dunia setiap tahun akan mengalami peningkatan. Hal tersebut tentu menjadi masalah tersendiri jika perencanaan awal dalam menghadapi masatua kurang baik yang dapat menyebabkan lansia di masa yang akan datang menjadi kurang sehat sehingga menjadi tidak produktif. Untuk itu diperlukan peningkatan pengetahuan tentang kesehatan termasuk pada penyakit tekanan darah tinggi (hipertensi). Hipertensi adalah meningkatnya tekanan darah yang di tandai dengan tekanan sistolik melebihi atau sama yaitu140 $\mathrm{mmHg}$ dan juga atau tekanan diastoliknya melebihi atau sama dari $90 \mathrm{mmHg}$.

Jumlah penderita Hipertensi di Provinsi Jawa Timur sebesar $22.71 \%$ atau sekitar 2.360.592 penduduk, dengan jumlah laki-laki 18.99\% (808.009 penduduk) dan perempuan sebesar $18.76 \%$ (1.146.412 penduduk). Di Tulungagung jumlah penderita hipertensi adalah 17,05\% dari jumlah penduduk dengan umur 18 tahun lebih (Dinkes Jatim 2018).

Faktor penyebab hipetensi antara lain adalah pola hidup yang kurang sehat contohnya terlalu sering mengkonsumsi fast food yang mengandung lemak serta makanan yang asin. Disamping itu, stres, merokok, mengkonsumsi alkohol dan kegemukan (obesitas), dapat juga mengakibatkan terjadinya hipertensi. Hipertensi apabila tidak mendapatkan penanganan dengan tepat akan beresiko terjadinya komplikasi seperti serangan jantung, stroke, gagal ginjal serta edema paru. Bahkan dapat mengakibatkan kematian apabila penanganan tidak segera diberikan (Kepmenkes RI, 2014).

Upaya untuk mencegah terjadinya komplikasi akibat hipertensi adalah dengan melaksanakan pemeriksaan tekanan darah dengan rutin (American Heart Association/AHA (2014). Faktor yang berpengaruh terhadap pemantauan tekanan darah serta pencegahan komplikasi dari hipertensi yaitu tingkat pengetahuan dan pengaturan pola makan yang salah (Alexander, dkk, 2007).Sedangkan penanganan dapat dilakukan secara farmakologis yaitu pemberian obat hipertensi dan non farmakologis antara lain yaitu dengan terapi komplementer misalnya dengan relaksasi otot progresif, pemberian aromaterapi, melakukan meditasi, terapi herbal, serta terapi dengan nutrisi; (2) konsumsi jus buah belimbing dan mentimun (Purwanto,2013; muniroh, dkk 2007).

Desa kromasan Kecamatan Ngunut Kabupaten Tulungagung adalah desa yang memiliki jumlah lansia 20\% dari jumlah penduduk. Sebagian besar lansia mengalami tekanan darah tinggi (hipertensi). Dari hasil survei awal yang dilakukan sebagian besar Lansia tidak tau kalau tekanan darah mereka tinggi karena tidak ada keluhan yang signifikan dirasakan mereka. Untuk itu dibutuhkan sosialisasi tentang penyakit darah tinggi, pencegahan serta penatalaksanaannya, termasuk salahsatunya yaitu pemeriksaan tekanan darah untuk mencegah meningkatnya penderita hipertensi di desa Kromasan.

\section{B. PELAKSANAAN DAN METODE}

Kegiatan pengabdian masyarakat ini dilakukan di Desa Kromasan, Kecamatan Ngunut, Kabupaten Tulungagung yaitu pada bulan September 2019. Jumlah peserta yang hadir 110 dengan latarbelakang usia di atas 45 th sehingga memiliki resiko 
menderita hipertensi. Alternative pemecahan masalah dilakukan dengan kegiatan meliputi : (1) pengukuran tekanan darah untuk mendeteksi adanya hipertensi; (2) memberikan informasi yang berkaitan dengan hipertensi seperti factor penyebab hipertensi, tanda gejala hipertensi, cara pencegahan dan penanganan hipertensi secara farmakologis dan non farmakologis; (3) mengajarkan cara membuat jus buah belimbing dan mentimun; (4) mengajarkan tehnik relaksasi otot progresif untuk penderita hipertensi.

\section{HASIL DAN PEMBAHASAN}

Proses kegiatan pengabdian masyarakat dilakukan beberapa tahap yang dibantu oleh mahasiwa maupun kader kesehatan. Kegiatan dimulai dengan melakukan pengisian daftar hadir peserta dilanjutkan pemberian pre test menggunakan questioner dengan metode wawancara.

Berdasarkan nilai dari pretest, dapat diketahui bahwasannya pengetahuan para lansia terkait hipertensi menunjukkan 77,3\% (85lansia) peserta penyuluhan mendapatkan nilai $<70$. Artinya sebagian besar peserta masih belum memiliki pengetahuan yang cukup terkait hipertensi dan penanganannya. Dilanjutkan pengukuran tekanan darah yang hasilnya ditulis pada lembaran kertas yang telah disediakan. Dari 110 lansia yang hadir, terdapat 41 (37,3\%) lansia dengan tekanan darahnya di atas batas normal $(>140-90 \mathrm{mmHg})$ sedangkan $69 \quad(62,7 \%)$ lansia memiliki tekanan darah normal dikarenakan sudah mengkonsumsi obat yang di berikan oleh Puskesmas Ngunut.

Pemberian informasi tentang hipertensi sangat penting bagi lansia untuk meningkatkan kesehatan serta mencegah terjadinya komplikasi yang tidak diinginkan akibat hipertensi. Upaya yang dilakukan tim utuk meningkatkan pengetahuan adalah dengan memberikan penyuluhan kesehatan tentang hipertensi. Penyuluhan dilakukan bersama dengan mahasiswa agar mahasiswa dapat mengaplikasikan ilmu yang didapat dari kampus dan juga dapat dijadikan sebagai pembelajaran bagi mahasiwa di komunitas.

Penyuluhan kesehatan merupakan suatu kegiatan yang dilakukan untuk meningkatkan pengetahuan masyarakat tentang kesehatan agar mereka mau dan dapat menjaga serta meningkatkan kesehatannya masing-masing (Notoatmodjo, 2010). Hal ini juga diperkuat oleh penelitian Machado att all (2017) pendidikan kesehatan terhadap masyarakat khususnya lansia telah menunjukkan strategi yang tepat untuk mendorong masyarakat untuk belajar dan berpartisipasi dalam pengobatan hipertensi.

Kegiatan selanjutnya adalah sosialisasi tentang terapi non farmakologi untuk hipertensi. Aktifitas yang dilakukan adalah mendemonstrasikan bagaimana membuat jus mentimun dan belimbing yang sudah terbukti menurunkan dari tekanan darah. Dalam hal ini lansia diberikan penjelasan tentang berapa perbandingan berat belimbing dan mentimun yang dibutuhkan, jenis buah yang dapat digunakan, serta berapa kali harus dikonsumsi. Jus buah belimbing dan mentimun berpengaruh dalam menurunkan tekanana darah. Bekerjanya jus buah tersebut yaitu menurunkan pengeluaran antidiuretic hormone $(\mathrm{ADH})$ dan megurangi rasa haus. Hipotalamus (kelenjar pituitari) memproduksi $\mathrm{ADH}$ yang diginjal berfungsi sebagai pengatur osmolalitas dan jumlah urine. Menurunnya kadar ADH akan menyebabkan jumlah 
urin yang dikeluarkan dari tubuh meiungkat. Hormon antidiuretik ini mempengaruhi kerja dari diastolik yang dapat menurunkan tekanan diastolic (Astawan, 2012). Penelitian Muniroh, dkk (2007) telah membuktikan bahwa jus buah belimbing yang dicanpur dengan mentimun diberikan 1 gelas perhari selama 2 minggu terbukti menurunkan secara siknifikan tekanan darah diastoleic maupun sistolik. Tahap ketiga mengajarkan teknik relaksasi otot progresif dan para lansia diminta untuk mempraktekkan secara langsung teknik relaksasi otot tersebut. Dari demonstrasi salah satu tim pengabmas, lansia mampu melakukan teknik relaksasi walaupun ada beberapa yang harus di bombing secara intensif. Namun pada akhirnya lansia tersebut mampu melakukan sendiri.

Menurut Porwanto (2013) hipertensi dapat diturunkan dengan melakukan terapi komplementer diantaranya dengan teknik relaksasi otot progresif. Relaksasi otot progresif merupakan suatu aktivitas dari otot dengan mencari otot-otot yang kaku serta menurunkan kekakuan tersebut dengan cara relaksasi supaya mendapatkan tubuh yang rileks.

Diakhir kegiatan para lansia kembali diberikan pertanyaan post test untuk mengetahui pemahaman lansia terhadap materi yang sudah diberikan. Hasil evaluasi yang didapatkan tergambar pada diagram berikut;

Gambar 1. Perbedaan Pengetahuan Lansia Sebelum penyuluhan dan Setelah Penyuluhan

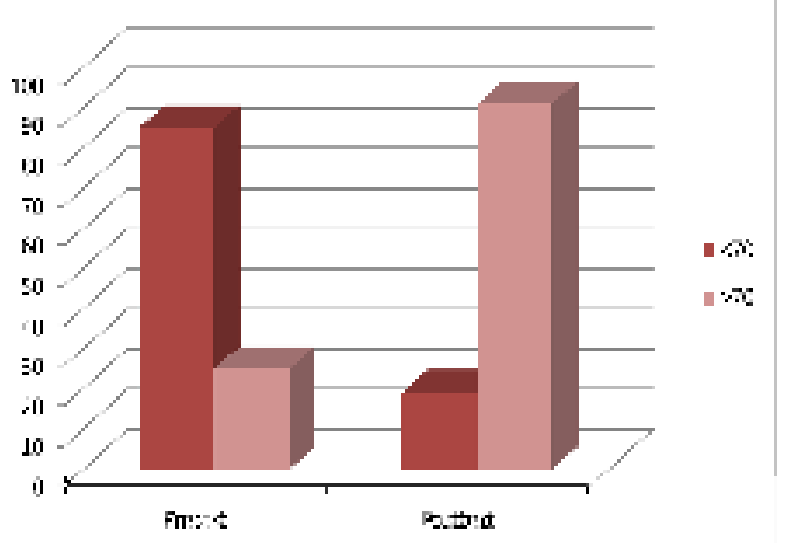

Berdasarkan nası pengamatan post test d1кetanuı banwa terdapat penıngkatan pengetahuan pada lansia setelah dilakukan penyuluhan kesehatan sebesar 82,7\% (91 lansia). Menurut Jeini Ester Nelwan (2019) tindakan promosi kesehatan berpengaruh terhadap peningkatan pengetahuan responden tentang hipertensi. Secara keseluruhan, kegiatan berjalan dengan lancer serta antusiasme dari lansia juga sangat baik. Pada saat penyampaian materi, lansia sudah cukup paham terkait dengan Hipertensi dan penanganannya. Hal ini dapat dilihat dari jawaban pertanyaan saat evaluasi yang diberikan kepada lansia mengalami peningkatan. Kegiatan semacam ini masih dibutuhkan oleh lansia dengan materi yang menyesuaikan dengan permasalahan yang dialami lansia di Desa Kromasan Kecamatan Ngunut Kabupaten Tulungagung. 


\section{PENUTUP}

\section{Simpulan}

Kegiatan pengabdian masyarakat yang meliputi penyuluhan, demontrasi membuat jus mentimun belimbing dan teknik relaksasi otot progressive sebagai terapi komplementer berjalan dengan lancar, walaupun ada beberapa lansia yang datang terlambat, begitupun pada saat menjelaskan dan mempraktekkan harus sering mengulang kembali mengingat peserta pengabdian adalah para lansia. Dukungan juga didapatkan dari berbagai sector terbukti dari banyaknya lansia yang datang saat kegiatan, difasilitasinya tempat penyuluhan oleh kader posyandu dan sosialisasi waktu pelaksanaan ke lansia maupun keluarganya oleh bidan desa.

Saran

Kepada para kader kesehatan desa Kromasan diharapkan bisa melanjutkan pendampingan kepada para lansia dalam pencegahan komplikasi hipertensi

Ucapan Terima Kasih

Ucapan terimakasih yang sebesar-besarnya kepada Pemerintah Daerah Desa Kromasan, kader kesehatan di Desa Kromasan serta Bidan Desa Kromasan yang banyak membantu terlaksananya kegiatan ini

\section{E. DAFTARPUSTAKA}

Alexander et al, 2014 Patient Knowledge and Awareness of Hypertension Is Suboptimal: Results From a Large Health Maintenance Organization. The Journal of Clinical Hypertension. 5. 254-260.

Astawan, Made. 2012. Cegah Hipertensi dengan Pola Makan. [Diakses tanggal 11 September 2019]. Tersedia dari: URL :www. Depkes.go.id.

Dinkes Jatim. 2018. Profil Kesehatan Provinsi Jawa Timur tahun 2018. Dinas Kesehatan Provinsi Jawa Timur, Surabaya..

Jeini Ester Nelwan. Pengaruh Penyuluhan Kesehatan terhadap Perubahan Pengetahuan Masyarakat tentang Hipertensi di Kota Manado. journal phwb. Dis. [serial online] vol. 1 no. 2, july2019 (pages 1-7) Tersedia dari: URL : https://www.researchgate.net/profile/oksfriani_sumampouw/publication/33472 9914 pengaruh_penyuluhan_kesehatan terhadap_perubahan_pengetahuan_ma syarakat tentang hipertensi_di kota manado/links/5d3d4dde92851cd0468c5a 1f/pengaruh-penyuluhan-kesehatan-terhadap-perubahan-pengetahuanmasyarakat-tentang-hipertensi-di-kota-manado.pdf

Kepmenkes RI. 2014. Hipertensi. Pusat Data dan Informasi Kementerian Kesehatan Rl, Jakarta Selatan. 
Lailatul M dkk. 2007. Pengaruh Pemberian Jus Buah Belimbing dan Mentimun terhadap Penurunan Tekanan Darah Sistolik dan Diastolik Penderita Hipertensi. The Indonesian Journal of Public Health, Dis. [serial online]Vol. 4, No. 1, 25-34. Tersedia dari: URL :https://media.neliti.com/media/publications/3872-ID-pengaruh-pemberianjus-buah-belimbing-dan-mentimun-terhadap-penurunan-tekanan-da.pdf

Machadoatt all, (2017). Culture circle in hypertensive elderly health promotion: experience report, Cienc Cuid Saude.

National Heart lung and Blood Institute. 2012. Hypertension. Diakses pada 8 Agustus 2019.

Notoadmodjo, Sukidjo. 2010. Kesehatan Masyarakat Ilmu dan Seni. Renika Cipta, Jakarta.

Purwanto, B. 2012. Hipertensi (Patogenesis, Kerusakan Target Organ dan Penatalaksanaan). Edisi Pertama. Cetakan Pertama. UPT Penerbitan dan Percetakan UNS (UNS press), Jawa Tengah.

Silviliyana, Mega dkk. 2018. Statistik Penduduk Lanjut Usia 2018. Badan Pusat Statistik, Jakarta. 